\title{
Social Network Addiction Scale: The Validity and Reliability Study of Adolescent and Adult Form
}

\author{
Ibrahim Gokdas (iD) 1, ${ }^{*}$, Yasar Kuzucu (iD) 2
}

\footnotetext{
${ }^{1}$ Department of Computer Education and Instructional Technology. Adnan Menderes University, Faculty of Education, 09010 Aydin / Turkey

${ }^{2}$ Psychological Counseling and Guidance in Education, Adnan Menderes University, Faculty of Education, 09010 Aydin / Turkey
}

\section{ARTICLE HISTORY}

Received: 31 December 2018

Revised: 19 July 2019

Accepted: 29 July 2019

\section{KEYWORDS}

Social network addiction scale, Social media addiction, Social media usage

\begin{abstract}
In this study, it was aimed to develop a valid and reliable social network addiction scale for adolescents and young adults. In the Exploratory Factor Analysis of the scale, the application was conducted to 425 high school students between 14-17 years of age and 310 young adults between 18-43 years of age. Confirmatory Factor Analysis was performed on a different group and for this purpose, 322 high school students and 197 young adults were included in the analysis. As a result of the analyses performed, the scale exhibited a-10-item and three-factor structure in both groups. The total variance explained was $71.51 \%$ for adolescents and $70.96 \%$ for young adults. The total Cronbach Alpha reliability coefficient of the scale was .87 for adolescents and .84 for young adults. With the 1 st and 2nd level Confirmatory Factor Analysis performed on a similar study group, a good model was revealed for both adolescents and young adults. The Social Network Addiction Scale developed within the scope of this study is thought to have the adequate validity and reliability structure that can be used to measure social network addiction levels of adolescents and young adults.
\end{abstract}

\section{INTRODUCTION}

Depending on the widespread use of the internet and the developments in information technologies, social networks are getting into our lives increasingly day by day. Social networks where texting and sharing (photos, documents, videos, etc.) are performed intensively affect the lives of many people from different age groups with the opportunities they offer. Depending on this development process, the use of social network has become an increasingly popular free time activity in many countries (Kuss \& Griffiths, 2011). Today, individuals tend towards social networks to participate in many different entertainment and social activities, including playing games, socializing, spending time, communicating and sending pictures (Allen, Ryan, Gray, Mclnerney, \& Waters, 2014; Ryan, Chester, Reece, \& Xenos, 2014). Such attractive

CONTACT: Ibrahim Gokdas $₫$ igokdas@gmail.com Department of Computer Education and Instructional Technology. Adnan Menderes University, Faculty of Education, 09010 Aydin / Turkey 
opportunities offered by social networks have an important role in the lives of many people from different age groups and affect their lives.

Social Network Websites that are defined as virtual communities where users can create individual and general profiles, interact with their friends and meet other people in line with common purposes (Kuss \& Griffths, 2011) have made significant changes in the way people communicate with others (Vilca \& Vallejos, 2015). Social networks, a new communication technology paradigm (Kang, Shin, \& Park, 2013; LaRose, Connolly, Lee, Li, \& Hales, 2014), have taken an important place in our lives with their popularity (LaRose, et al., 2014). According to 2017 data, the population of the world is 7,476 billion people and 3,773 of it are internet users. 2,789 billion people are actively using social networks. According to the usage ratio of 2016, the number of internet users has increased by 354 million with a $10 \%$ rise and the number of social media users has increased by 482 million with a $21 \%$ rise. Following the first Global Digital Report for internet usage in January 2012, the number of global users has increased more than $80 \%$ in five years (We are Social, 2017). When the annual change ratios are taken into account, the increase in the number of social network users is particularly noteworthy. A meta-analysis conducted found out that about $6 \%$ of the world's population has internet addiction (Cecilia \& Yee-lam, 2014). This ratio corresponds to about 226 thousand of people when considered for 2017 data.

The increase in the ratio of users caused social networks to be considered as a normal modern phenomenon within the society (Boyd \& Ellison, 2007). However, the increase in the time that people spend online on social networks (Kuss \& Griffiths, 2011) has brought together the concerns about addiction and social network use (Andreassen, 2015; Griffiths, Kuss \& Demetrovics, 2014). There is also increasing evidence that social network addiction is a mental problem that occurs in adolescents (Pantic, 2014; Ryan et al., 2014).

It is believed that the developments in the features of information technologies (laptop computers, tablet PCs, smartphones, etc.) have a significant role in the widespread use of social networking and the increase of addiction because new technologies support easy and fast access to social networking sites and it is known that excessive use of such new technologies can be addictive especially for adolescents (Echeburúa \& de Corral, 2010). When the user profile of social networks is investigated, it is seen that especially adolescents are the most intensive user group (Van den Eijnden, Lemmens, \& Valkenburg, 2016; Vilca \& Vallejos, 2015). For example, when the data of 2017 is analyzed, it is noted that about $73 \%$ of Facebook users are the individuals between the age of 18-34, 9\% of the users are between the age of 13-17and 10\% of the users are between the age of 35-44 (We are Social, 2017). This intensity is particularly worrying in that the risk of social network addiction in especially adolescents and young adults has increased and it has caused adolescents to move away from the necessary activities for their improvement. (Park, Kim, \& Cho, 2008).

The egocentric nature of social networks push people towards problematic use by contributing to the development of addiction behaviors. Similarly, social networks lead individuals to exhibit themselves different from what they really are and live delightful experiences (Kuss \& Griffths, 2011). Furthermore, the opportunities offered by social networks make users happy (Choi \& Lim, 2016; Yang, Liu, \& Wei, 2016) and create excitement by filling a psychological gap in the lives of individuals (Echeburúa \& De, 2010; Yang et al., 2016). Together with the popularity achieved by social networks and many benefits they provide the users (Kuss \& Griffiths, 2012), spending too much time in a social network (Can \& Kaya, 2016) is considered a sign of social network addiction (Gao, Liu, \& Li, 2017; Turel \& Serenko, 2012) and may cause psychological disorders (Salehan \& Negahban, 2013).

Despite the fact that the latest edition of the Diagnostic and Statistical Manual of Mental Disorders (DSM-5) recognize Internet addiction as a temporary disorder in the appendix of this 
guide (APA, 2013), social network addiction does not still hold a status in DSM-5. The fact that social network addiction is not included in DSM-5 creates the impression that social network addiction is not a psychological problem (Van den Eijnden et al., 2016). However, there are also studies that do not support this situation (Pantic, 2014; Ryan, Chester, Reece, \& Xenos, 2014). The fact that there are no explicit definitions and precautions for social network addiction affects doing researches about these widespread behaviors negatively (Van den Eijnden et al., 2016).

Different research suggests that excessive use of social networks is associated with anxiety, frustration, intolerance, anger, low self-esteem, impoverishment of social relationships, decrease in academic performance, verbal or physical aggression, and depression tendency (Cheung \& Wong, 2011; Huang \& Liang, 2009; Satici \& Uysal, 2015). Besides, it was found that excessive use of social networks might lead to such negative conclusions as sleeping disorders (Dewald, Meijer, Oort, Kerkhof, \& Bögel, 2010) and procrastination of sleeping time (Brunborg, Mentzoni, Molde, Myrseth, Skouverøe, Bjorvatn et al., 2011; Suganuma, Kikuchi, Yanagi, Yamamura, Morishima, Adachi et al., 2007).

Considering the psychological, social, economic, cultural and educational losses caused by social network addiction, it is significant to determine the level of social network addiction. However, the number of studies regarding social network addiction are insufficient (Kuss \& Griffths, 2011; Andreassen, 2015). When the researches conducted are analyzed, it is possible to get the impression that Facebook addiction has the same meaning as social network addiction (Ryan et al., 2014; Griffiths, Kuss, \& Demetrovics, 2014; Van den Eijnden, et al., 2016). Addiction scales developed in this respect are focused on Facebook addiction or problematic Facebook usage (Kuşay, 2013; Andreassen, 2015) and have become intense after 2011 (Ryan et al., 2014). Social networks exhibit different characteristics in terms of functionality and expediency. For example, social networks such as Blogger etc. for publishing content, YouTube, Slideshare etc. for sharing, Messenger, Skype etc. for chatting, Facebook, LinkedIn etc. for getting to know other people, Twitter, Twitpic etc. for expressing short ideas, Friendfeed, Foursquare etc. for sharing life are widely used (Kuşay, 2013). On the other hand, the ratio of people sharing on Instagram, Pinterest or Twitter instead of Facebook is increasing rapidly. Besides, the ratio of WhatsApp users from different age groups is also increasing rapidly. YouTube is a tool where especially adolescents watch and share videos. Today, the number of present social network websites is over 100 (Pantic, 2014). Lots of people from different age groups actively and intensely use more than one of these, not just one. Therefore, social networks have a strong social impact on the lives of their users.

In spite of the popularity of social network use among people, empirical studies analyzing the addiction to these networks are insufficient (Ryan et al., 2014). Considering this fact, it is important to have psychological tools to be able to identify early possible social network addiction (Vilca \& Vallejos, 2015). However, the diversity in social networks makes the studies regarding social network addiction problematic. The first reason for this is the rapid change in the social network environment and the expansion of its interactive functions. This will cause the measurement tools targeting specific social networks to lose their up-to-datedness easily. The second reason is that the criterions that may cause social network addiction vary. These reasons will cause problems in the process in comparing the related researches carried out (Van den Eijnden et al., 2016). The distinctive nature of each social network environment and the differences in the opportunities it offers reveals that social network addiction should be considered as different from internet or Facebook addiction alone. Therefore, the development of studies on social network addiction requires the development and validation of a general social network addiction scale (Van den Eijnden et al., 2016). 
When the literature was examined examined (Esgi, 2016; Fırat \& Barut, 2018; Şahin, 2018; Tutgun-Ünal \& Deniz 2015; Ülke, Noyan, \& Dilbaz, 2017; Van den Eijnden et al., 2016), it was found that various scales had been developed regarding social network addiction in recent years. Insufficient number of researches in the field and the need for scale development in this regard have been the main problem. However, it can be seen that some of the measurement tools developed in Turkish language are directed to young adults and adults (Esgi, 2016; Tutgun-Ünal, \& Deniz, 2015; Ülke, Noyan, \& Dilbaz, 2017) while some others are directed to adolescents and young adults (Fırat \& Barut, 2018; Şahin, 2018). Besides, the study of Taş (2017), who conducted the Turkish adaptation study of the short form of social media addiction scale developed by Van den Eijnden et al. (2016) for adolescents and young adults, also involves adolescents and young group. In the international field literature, no social network addiction scale involving a large target group was found. In this regard, Social Media Disorder Scale developed by Van den Eijnden et al. (2016) involves the group of 10-17 years of age. Bergen Social Media Addiction Scale (BSMAS) is a modified version of the previously approved Bergen Facebook Addiction Scale (BFAS) (Andreassen et al., 2012). In the scales, the word "Facebook" was replaced by the word "social media" and social media was defined as "Twitter, Instagram and etc.". Bergen Facebook Addiction Scale (Andreassen, Torsheim, Brunborg, \& Pallesen, 2012) was later adapted as Bergen Social Media Scale (Andreassen, Pallesen, \& Griffiths, 2017). The original scale involved university students.

When evaluated in general, it can be revealed that the scales in the literature for social network addiction differ from each other in terms of the target group. Furthermore, as the factor structures of the scales also differ from each (Esgi, 2016; Firat \& Barut, 2018; Şahin, 2018; Taş, 2017; Turgut-Ünal \& Deniz 2015; Ülke, Noyan, \& Dilbaz, 2017; Van den Eijnden et al., 2016), it is considered that they will be insufficient for the studies to be conducted and in providing comparability among different age groups. Therefore, there is a need for an easily applicable scale that involves a target population of wider age range.

Based on these basic justifications, the main purpose of the study was to develop a highly valid and reliable social network addiction measurement tool for adolescents, young adults and adults. The research is deemed important in terms of involving different target groups as adolescents, young adults and adults with regard to their social network addiction levels.

\section{METHOD}

\subsection{Study Group and Process}

Social Network Addiction Scale (SNAS) was implemented to 461 students between the ages of 15 and 18 from five different high schools studying in Efeler, the central district of Aydin province in the spring semester of 2016-2017 academic year. The participants were given the information that the data would not be considered personally and that there would not be only one correct answer for everyone. The application lasted about 15-20 minutes. However, because of faulty and missing information, and after excluding extreme values, 425 forms were included in the evaluation. In the first stage, Exploratory Factor Analysis (EFA) was performed on the data collected from 425 students. In order to test the results of EFA with Confirmatory Factor analysis (CFA), additional data was collected from 371 high school students of the same age group. Participant students were determined by convenience sampling and it was noted from each level of education that they were using at least one social network and were voluntarily participating. SNAS was also applied to the adult group. For the adult group, 750 people who had undergraduate education at Adnan Menderes University and who graduated from a higher education institution and participated in pedagogical formation training were asked to fill in the form via e-mail. The form of the scale was organized online. A total of 367 participants completed the scale during the three-week period. However, a total of 310 forms were included 
in the evaluation after excluding extreme values and EFA was performed on this dataset. In order to test the results of the EFA with CFA, 430 people were e-mailed and 201 of them responded. Nonetheless, 197 data were included in the evaluation after the extreme values were excluded. The distribution of the study groups is given in Table 1 and Table 2.

Table 1. The distribution of the study group for the Exploratory Factor Analysis

\begin{tabular}{|c|c|c|c|c|c|c|c|c|c|}
\hline \multirow[b]{3}{*}{ Age } & \multicolumn{4}{|c|}{ Adolescent (14-17 years of age) } & \multirow[b]{3}{*}{ Education } & \multicolumn{4}{|c|}{ Adult (18-45 years of age) } \\
\hline & \multicolumn{2}{|c|}{ Applied } & \multicolumn{2}{|c|}{ Valid } & & \multicolumn{2}{|c|}{ Applied } & \multicolumn{2}{|c|}{ Valid/Returned } \\
\hline & $\mathrm{f}$ & $\%$ & $\mathrm{f}$ & $\%$ & & $\mathrm{f}$ & $\%$ & $\mathrm{f}$ & $\%$ \\
\hline 14 & 98 & 21,3 & 91 & 21,4 & Undergraduate & 188 & 51.2 & 158 & 51 \\
\hline 15 & 108 & 23,4 & 98 & 23,1 & Graduate & 179 & 48.8 & 152 & 49 \\
\hline 16 & 153 & 33,2 & 140 & 32,9 & Total & 367 & 100 & 310 & 100 \\
\hline 17 & 102 & 22,1 & 96 & 22,6 & Age & & & & \\
\hline \multirow[t]{2}{*}{ Total } & 461 & 100,0 & 425 & 100,0 & $18-22$ & 172 & 46,5 & 135 & 43.5 \\
\hline & & & & & $23-27$ & 130 & 35,1 & 110 & 35.4 \\
\hline Gender & & & & & $28-32$ & 32 & 8,6 & 30 & 9.7 \\
\hline Male & 125 & 27,1 & 114 & 26,8 & $33-37$ & 23 & 8,6 & 23 & 7.5 \\
\hline Female & 336 & 72,9 & 311 & 73,2 & 38 and above & 12 & 3,8 & 12 & 3.9 \\
\hline \multirow[t]{5}{*}{ Total } & 461 & 100,0 & 425 & 100,0 & & 367 & 100 & 310 & 100 \\
\hline & & & & & Gender & & & & \\
\hline & & & & & Female & 226 & 61,6 & 193 & 62.2 \\
\hline & & & & & Male & 141 & 38,4 & 117 & 37.8 \\
\hline & & & & & Total & 367 & 100 & 310 & 100 \\
\hline
\end{tabular}

Table 2. The distribution of the study group for the Confirmatory Factor Analysis

\begin{tabular}{|c|c|c|c|c|c|c|c|c|c|}
\hline \multirow{3}{*}{ Age } & \multicolumn{4}{|c|}{ Adolescent (14-17 years of age) } & \multirow[b]{3}{*}{ Education } & \multicolumn{4}{|c|}{ Adult (18-45 years of age) } \\
\hline & \multicolumn{2}{|c|}{ Applied } & \multicolumn{2}{|c|}{ Valid } & & \multicolumn{2}{|c|}{ Applied } & \multicolumn{2}{|c|}{ Valid/Returned } \\
\hline & $\mathrm{f}$ & $\%$ & $\mathrm{f}$ & $\%$ & & $\mathrm{f}$ & $\%$ & f & $\%$ \\
\hline 14 & 84 & 22.6 & 73 & 24,2 & Undergraduate & 100 & 30,3 & 78 & 39,6 \\
\hline 15 & 96 & 25.9 & 90 & 30,2 & Graduate & 330 & 69,7 & 119 & 60,4 \\
\hline 16 & 150 & 40.4 & 126 & 31 & Total & 330 & 100 & 197 & 100 \\
\hline 17 & 41 & 11 & 33 & 14,6 & Age & & & & \\
\hline \multirow[t]{2}{*}{ Total } & 371 & 100 & 322 & 100 & $18-22$ & 19 & 9.6 & 19 & 9,6 \\
\hline & & & & & $23-27$ & 77 & 38.4 & 79 & 40,1 \\
\hline Gender & & & & & $28-32$ & 45 & 22.4 & 46 & 23,4 \\
\hline Male & 148 & 39,9 & 117 & 36,3 & $33-37$ & 23 & 11.6 & 23 & 11,7 \\
\hline Female & 223 & 60,1 & 205 & 63,7 & 38 and above & 30 & 18 & 30 & 15,2 \\
\hline \multirow[t]{5}{*}{ Total } & 371 & 100,0 & 322 & 100,0 & Total & 201 & 100 & 197 & 100 \\
\hline & & & & & Gender & & & & \\
\hline & & & & & Female & 113 & 56.2 & 110 & 55.8 \\
\hline & & & & & Male & 88 & 43.8 & 87 & 44.2 \\
\hline & & & & & Total & 201 & 100 & 197 & 100 \\
\hline
\end{tabular}

\subsubsection{The Development of Social Network Addiction Scale}

In order to develop a measurement tool for social network addiction, literature was analyzed and questions were prepared taking into account especially the studies of Young (1998), Griffiths (2005), Block (2008), Tao (2010), and Van den Eijnden et al., (2016). By obtaining the views of three experts who had $\mathrm{PhD}$ degrees in the field of psychology and who studied on internet addiction, five inappropriate items with similar meanings were removed from the draft form. The remaining 30 items were taken into the trial form of the scale. All of the items are positive statements and they are in the 5-point- Likert form ranked as 1=Never, 2=Rarely, $3=$ Sometimes, $4=$ Often, $5=$ Very Often. For the items in the trial form, EFA, CFA and item analysis were performed. 


\subsection{Data Collection Tools}

In order to determine the criterion validity of the SNAS Adolescent Application, the relationship of the Problematic Mobile Phone Use Scale with the SNAS was analyzed. For the criterion validity of SNAS Adult Application, the relationship of it with the Internet Addiction Scale was analyzed.

\subsubsection{Problematic Mobile Phone Use Scale}

In order to determine the criterion validity of the SNAS, the Problematic Mobile Phone Use Scale developed by Augner \& Hacker (2012) and adapted by Tekin, Güleş, \& Çolak (2014) was utilized. Problematic Mobile Phone Use Scale is composed of three sub-dimensions in total. The first sub-dimension is defined as "addiction" (9 questions), the second sub-dimension is defined as "social relations" ( 7 questions), and the third sub-dimension is defined as "results" (10 questions). In the adaptation study, the three-factor scale explains $45 \%$ of the total variance. The Cronbach Alpha value of the scale was found 0.85. Besides, the Cronbach Alpha value of the first sub-dimension (addiction) was found 0.73, that of the second sub-dimension (social relations) was found 0.60 , and that of the third sub-dimension(results) was found 0.85 (Tekin et al., 2014).

\subsubsection{Internet Addiction Scale}

The Internet Addiction Scale developed by Young (1998) and adapted to Turkish by Cakir and Horzum (2008) was used to determine the criterion validity of the scale. The Turkish adaptation of the scale is composed of three sub-dimensions in total. The first sub-dimension is defined as "preferring being online to daily life" ( 8 items), the second sub-dimension is defined as "having desire to increase the duration of being online" ( 7 items), and the third sub-dimension is defined as "the problems arising from being online" (4 items)". The total variance explained was $52.83 \%$ and the total Cronbach Alpha internal consistency coefficient was found .90 (Çakır \& Horzum, 2008).

\subsection{Data Analysis}

SPSS 22.0 (SPSS Inc.) and LISREL 8.80 (Joreskog \& Sorbom, 1993) statistical package programs were used in the analysis process. The data of the scale applied separately to adolescents and adults were analyzed using EFA and CFA techniques for the construct validity. By examining the measurement invariance in adolescent and adult samples, it was tested whether the measurement tool was appropriate for the comparisons between groups. Furthermore, item-test score correlations, test-retest scores correlation, internal consistency McDonald Omega coefficient (McDonald, 1999) were calculated. T-test was performed to test whether the items of the scale distinguished between the lower and upper $27 \%$ groups. Item Response Theory (IRT) was used to check the reliability results obtained.

\section{FINDINGS}

\subsection{Adolescent Application}

\subsubsection{Pre-analyses}

In order to determine whether the data showed normal distribution or not, Skewness and kurtosis values were examined. Skewness was found .61 and Kurtosis was found -.03. The fact that both values are between the range of $-1,+1$ implies that they show normal distribution. In addition to Skewness and Kurtosis analyses, Kolmogorov-Smirnov test results ( $p>.05$ ) support normal distribution.

Kaiser Meyer Olkin (KMO) coefficient was used to determine whether the data structure was appropriate for factor analysis in terms of the sample size of the SNAS adolescent application. As a result of the analysis, KMO value was determined as 0.87 . The fact that KMO value is 
high means that each variable in the scale can be estimated well by the other variables (Çokluk, Şekercioğlu, \& Büyüköztürk, 2012). Another indicator for the appropriateness of the data for factor analysis is the Anti-image Correlation Matrix. These values need to be above 0.5 and the values below this must be excluded from the analysis (Field, 2009). The diagonal values for each variable in the anti-image matrix vary between .80 and .91 . The fact that all the values at the intersection point are above 0.5 indicates that it is accurate to include all the items in the scale.

\subsubsection{The Validity of Social Network Addiction Scale Adolescent Application}

After determining that the sample size is appropriate for factor analysis, the factor structure for the construct validity of the scale was determined by performing EFA. The purpose of performing EFA is to gather the variables that are related to each other and that measure the same quality together, and to reduce the number of items forming the scale (Aksu, Eser, \& Güzeller, 2017). CFA was performed to test whether the restricted structure defined by EFA was verified as a model (Çokluk, Şekercioğlu, \& Büyüköztürk, 2012).

After the first factor analysis with a total of 30 items, the items were collected in 5 subdimensions, with eigen values greater than 1 . However, the items numbered 1, 3, 4, 7, 8, 10, $11,12,13,14,15,18,19,20,21,22,24,25,26,27$ with factor loadings below 0.30 and that were overlapping were gradually removed from the scale. Factor analysis was made again by removing one item at each step. As a result, 20 items were removed from the scale and the remaining 10 items were collected in 3 sub-dimensions. The items of each sub-dimension were examined and it was determined that they were grouped under the factor to which they were related. To clarify the relationship among factors, direct oblimin rotation (the oblique rotation technique of Principal Component Analysis) was used. As a result of the EFA performed by using the oblimin rotation method, it was found that the eigenvalue of the first factor was 4.6 and the variance it explained was 26.27, the eigenvalue of the second factor was 1.49 and the variance it explained was 25.61, the eigenvalue of the third factor was 1.05 and the variance it explained was 19.63 . The total variance explained by the scale was found $71.51 \%$. When the eigenvalues and cumulative variance percentages of the three factors were taken into consideration, it was determined that the scale had three factors. The findings obtained as a result of the EFA performed for SNAS Adolescent Application revealed that the construct validity of the scale was sufficient. The factors formed after EFA and the items collected under each factor are given in Table 3.

When Table 3 is examined, it can be seen that the first factor is composed of 4 items $(2,5,6$, 9 ), the second factor is composed of 3 items $(28,29,30)$ and the third factor is composed of 3 items $(16,17,23)$. The results reveal that each item is clustered under a factor that is related with a value that is more than twice as much as the factor loading value that they have in other factors. This finding, which shows that the items differentiate in terms of factors, support the construct validity of the scale.

When the scree plot conducted to reveal the factor structure of the scale is analyzed, it can be seen that the graph curve shows a sharp decrease till the third factor and that the curve proceeds horizontally after the third factor (Figure 1). This finding supports the three-factor structure of the scale. 
Table 3. Factor Loadings of SNAS Adolescent Application

\begin{tabular}{|c|c|c|c|c|c|}
\hline \multirow{2}{*}{ Factors } & & \multirow{2}{*}{ Items } & \multicolumn{3}{|c|}{ Factor Loadings } \\
\hline & & & 1 & 2 & 3 \\
\hline \multirow{4}{*}{$\begin{array}{l}\text { Control } \\
\text { Difficulty }\end{array}$} & Q1 & $\begin{array}{l}\text { I find myself surfing the social networks in most of my } \\
\text { daily life. (5) }\end{array}$ & .890 & .030 & .115 \\
\hline & Q2 & I spend most of my time in social networks. (9) & .807 & .034 & .009 \\
\hline & Q3 & $\begin{array}{l}\text { I do not give up using social networks even if they affect } \\
\text { my daily life.(6) }\end{array}$ & .765 & .036 & .148 \\
\hline & Q4 & I make an effort to use social networks every day. (2) & .716 & .128 & .126 \\
\hline \multirow{3}{*}{$\begin{array}{l}\text { Negativeness in } \\
\text { Social Relations }\end{array}$} & Q8 & I feel happy to share my ideas on social networks. (23) & .111 & .887 & .017 \\
\hline & Q9 & $\begin{array}{l}\text { I prefer to share my daily activities on social networks. } \\
\text { (16) }\end{array}$ & .086 & .768 & .082 \\
\hline & Q10 & I express myself better on social networks. (17) & .082 & .685 & .097 \\
\hline \multirow{3}{*}{$\begin{array}{l}\text { Decrease } \\
\text { Functions }\end{array}$} & Q5 & $\begin{array}{l}\text { The time I allocate for my work/lessons have decreased } \\
\text { since I began to use social networks. (29) }\end{array}$ & .013 & .009 & .911 \\
\hline & Q6 & $\begin{array}{l}\text { My performance at work/school have decreased since I } \\
\text { began to use social networks. (28) }\end{array}$ & .013 & .026 & .909 \\
\hline & Q7 & $\begin{array}{l}\text { I have begun to have problems focusing on my } \\
\text { work/school since I began to use social networks. (30) }\end{array}$ & .037 & .016 & .875 \\
\hline
\end{tabular}

Notes: $\mathrm{N}=425 * \mathrm{p}<.05 * * \mathrm{p}<.01$

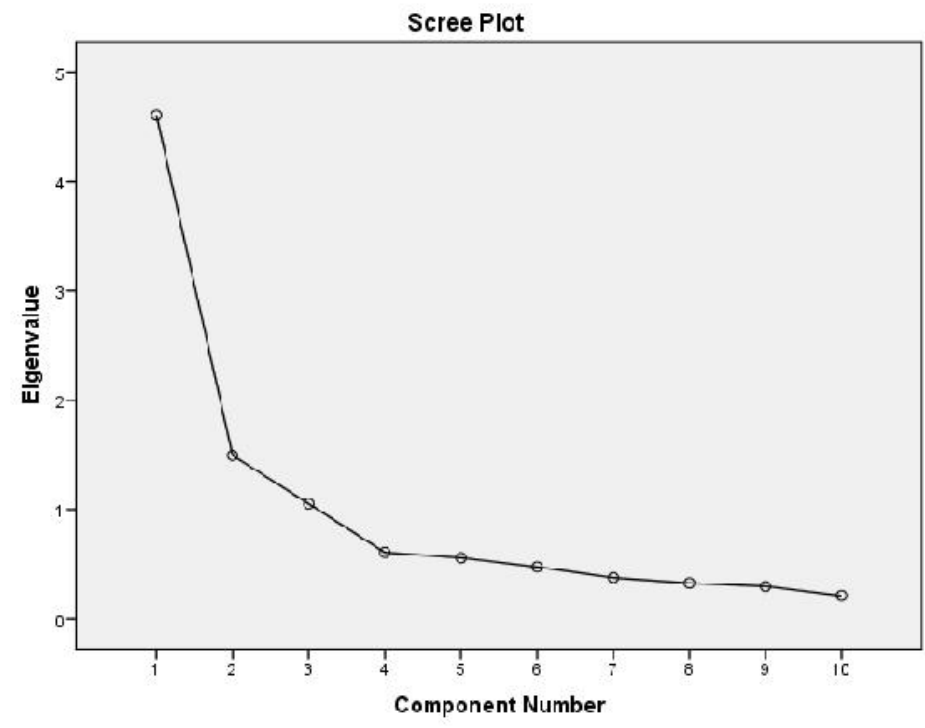

Figure 1. SNAS Adolescent Application Scree Plot Graph

Following this phase, the items in each sub-dimension were examined as a whole and a factor structure consistent with the theoretical framework was observed. Within this context, in relation to the literature on addiction, the first sub-dimension of the scale was named as "Decrease in Functions", the second sub-dimension was named as "Control Difficulty" and the third sub-dimension was named as "Negativeness in Social Relations". In order to determine whether there were significant correlations among the factors forming SNAS Adolescent Application, Pearson Product-Moment Correlation Analysis was performed. It was revealed that the relationship of "Control Difficulty" factor with "Decrease in Functions" and "Negativeness in Social Relations" factors was found as .52 and .41, respectively; and the relationship between "Decrease in Functions" and "Negativeness in Social Relations" was determined as .30. The results obtained, consistent with the literature (Şahin, 2018), show that there was a positive significant relationship among all the sub-dimensions of the scale $p \leq 001$. 
First level and second level Confirmatory Factor Analysis (CFA) was performed to evaluate the applicability of the three sub-dimensions of SNAS Adolescent Application to the data obtained from the study group. The models obtained from these analyses are given in Figure 2 and Figure 3.

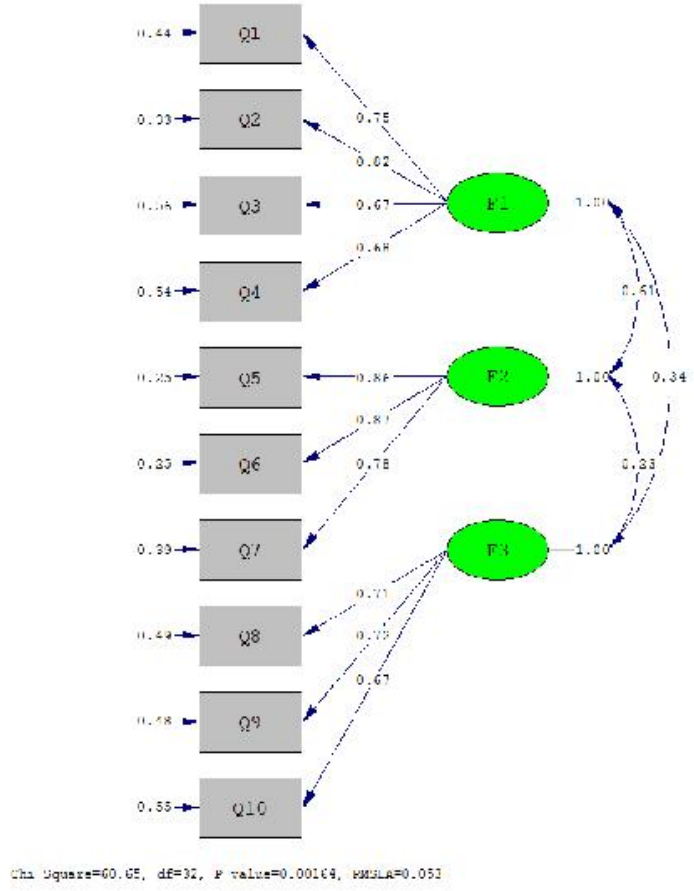

Figure 2. SNAS Adolescent Application $1^{\text {st }}$ Level CFA

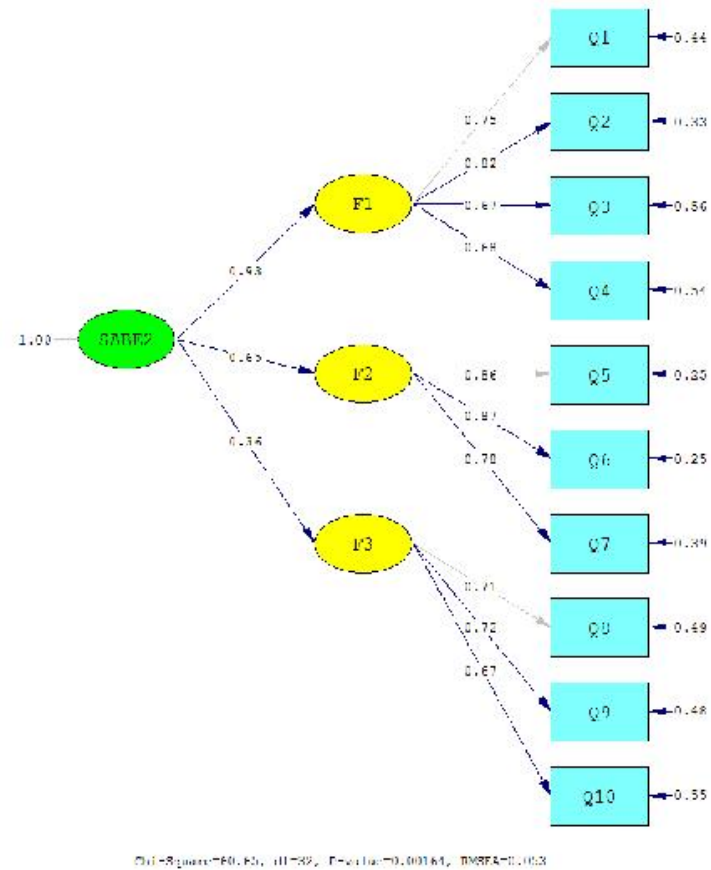

Figure 3. SNAS Adolescent Application $2^{\text {nd }}$ Level CFA

First and second level CFA was performed for the 10-item structure that was collected under three factors as a result of EFA performed for SNAS adolescent application. When the findings revealed as a result of CFA were evaluated, $\chi 2 / \mathrm{sd}$ ratio for the first and second level was determined as $2.08\left(\chi^{2} / \mathrm{sd}=66.65 / 32\right)$. The fact that $\chi 2 / \mathrm{sd}$ ratio obtained as a result of first and second level CFA is between $2.0 \leq 3.0$ correspond to an acceptable fit. RMSEA fit index value was determined as 0.053 as a result of first and second level CFA. The fact that RMSEA fit index value is below 0.08 can be interpreted as acceptable fit (Kline, 2015). It was determined that, among the fit index values related to the model as a result of the first and second level CFA, AGFI was 0.94, GFI was 0.96, standardized RMR fit index value was 0.041, NFI fit index value was 0.97 , and CFI fit index value was 0.99 . When all the values related to data fit of the model are taken into consideration, it can be seen that the model formed shows adequate level of fit with the data.

An additional CFA was performed to support the multifactorial structure of SNAS Adolescent Application; the results of first and second level factor analysis were compared with the 1-factor analysis of the scale. Scale was assumed one dimensional and it produced following statistics: $\chi 2 / \mathrm{sd}$ ratio of the fit values used in the model comparisons was calculated as 16.5 $(\chi 2 / \mathrm{sd}=580.1 / 35, \mathrm{NFI}=0.77, \mathrm{GFI}=0.73, \mathrm{CFI}=0.78 \mathrm{RMSEA}=0.22)$. The results obtained showed that the 1-factor structure had poorer fit values than the 3-factor structure. In order to determine the criterion validity of SNAS Adolescent Application, the relationship between Problematic Mobile Phone Use Scale (PMPUS) and SNAS Adolescent Application was examined with Pearson Product-Moment Correlation Analysis and it was found that there was a positive $(r=.55)$ and statistically significant $(\mathrm{p} \leq 001)$ relationship between the two variables. 


\subsubsection{The Reliability of SNAS Adolescent Application}

Item analysis was conducted to determine the contribution of the items in the scale to the implicit structure they belong to, and to measure the level of discrimination between the items with and without relevant characteristics in the structure they belong to (Erkuş, 2012). It was revealed that item total correlation coefficients varied between .41 and .73. On the condition that the items are congeneric measurements, McDonald Omega coefficient is used (McDonald, 1999). McDonald Omega coefficient of the overall scale was calculated as .87. The reliability analysis for each factor of the scale was also conducted. As a result of the analysis performed for this purpose, it was found for the first factor that McDonald Omega coefficient was .76 and item total correlation coefficients varied between .61 and .72. For the second factor, McDonald Omega coefficient was found .81 and item total correlation coefficients varied between.51 and .56. For the third factor, McDonald Omega coefficient was found .72 and item total correlation coefficients varied between .77 and .83 . It can be seen that the reliability values of the overall and sub-dimensions of the SNAS Adolescent Application are generally acceptable values for social sciences.

It was also analyzed whether there was a significant difference between the individuals with low scores and high scores. As a result of the t test conducted to determine the difference between the responses of the individuals in the lower $27 \%$ group and the responses of the individuals in the upper $27 \%$ group to all the items in the scale, the items' $t$ values varied between $4.14(\mathrm{p}<.001)$ and $10.67(\mathrm{p}<.001)$ and a significant difference was found. In the analysis performed, it was found that the variances were heterogeneous.

Item Response Theory (IRT) was used to confirm the reliability results obtained. IRTPRO 4.2 software was used to analyze with IRT. For this purpose, the three-factor structure fit of the scale was analyzed by using the two-parameter logistic model (2PL) to examine the items. The item difficulty (a) and item discrimination power (b) that were considered important were analyzed according to this formulation (Hambleton, Swaminathan \& Rogers, 1991). Besides, $X^{2}$ value, which is the measure of item-model fit, and the items that were insignificant $(\mathrm{p}<=$ $0,01)$ were also examined. The calculated " $a$ " and " $b$ " item parameter values and $X^{2}$ values are given in Table 4.

Table 4. Parameter values in terms of SNAS Adolescent Application according to IRT

\begin{tabular}{cccccccccccccc}
\hline Item & $a$ & s.e. & $b_{1}$ & s.e. & $b_{2}$ & s.e. & $b_{3}$ & s.e. & $b_{4}$ & s.e. & $X^{2}$ & $d f$ & $p$ \\
\hline 1 & 1.39 & 0.17 & -2.69 & 0.33 & -0.90 & 0.15 & 0.79 & 0.13 & 2.45 & 0.27 & 57.51 & 57 & 0.457 \\
2 & 1.62 & 0.20 & -2.33 & 0.26 & -0.37 & 0.11 & 1.25 & 0.14 & 3.00 & 0.33 & 33.92 & 49 & 0.950 \\
3 & 1.41 & 0.17 & -1.58 & 0.20 & 0.06 & 0.11 & 1.31 & 0.16 & 3.59 & 0.44 & 50.42 & 58 & 0.750 \\
4 & 1.38 & 0.17 & -1.41 & 0.19 & 0.04 & 0.11 & 0.90 & 0.13 & 1.97 & 0.22 & 60.59 & 67 & 0.697 \\
5 & 2.82 & 0.39 & -0.66 & 0.09 & 0.11 & 0.09 & 0.92 & 0.12 & 1.67 & 0.17 & 67.38 & 51 & 0.061 \\
6 & 2.79 & 0.42 & -0.46 & 0.08 & 0.45 & 0.10 & 1.22 & 0.15 & 2.01 & 0.21 & 102.04 & 49 & 0.058 \\
7 & 2.36 & 0.30 & -0.55 & 0.09 & 0.46 & 0.10 & 1.38 & 0.16 & 2.24 & 0.24 & 70.02 & 49 & 0.045 \\
8 & 0.65 & 0.12 & -1.65 & 0.64 & 2.11 & 0.76 & 4.84 & 1.62 & 8.13 & 2.74 & 90.14 & 79 & 0.183 \\
9 & 0.47 & 0.12 & -0.45 & 0.28 & 2.16 & 0.58 & 4.87 & 1.26 & 7.37 & 1.95 & 82.48 & 70 & 0.145 \\
10 & 0.64 & 0.13 & -0.52 & 0.22 & 1.22 & 0.28 & 3.39 & 0.65 & 5.51 & 1.10 & 76.31 & 64 & 0.139 \\
\hline
\end{tabular}

The item discrimination parameter provides information about the quality of the item. While items with A parameter value below 0.5 are regarded as weak in terms of discrimination (De Beer, 2004), those above 1 are not deemed adequate (Gültaş, 2014). From Table 4, it can be seen that all the values except for the value of item 9 are sufficient and the values of item 8 and 10 are at the borderline. Item discrimination serves to differentiate between the individuals with 
low and high social network addiction. Item difficulty indicates where the item is functional on the social network addiction level of the item. High level of "b" value exhibits that the item is functional or it measures among the individuals with high addiction levels, whereas low level of " $b$ " value indicates that the item is functional or it measures among the individuals with low addiction levels. Item difficulty value varies between -2.69 and 8.14. It was noted that while the first threshold value of the scale (Likert 1 and 2 interval) was about -2 , the second threshold value was 0 , the third threshold value was 1 , and the fourth threshold value varied between 2 and 8 . This suggests that the scale is better discriminated in the individuals with high social network addiction. It was found that from the $X^{2}$ values indicating item model fit, only item 7 was significant and did not meet the model fit. This item was not removed from the scale due to the fact that it had one of the highest factor loadings with a factor loading of .84 , and that its item total correlation was high (.60) as a result of EFA.

\subsection{SNAS Adult Application}

\subsubsection{Pre-analyses}

KMO coefficient was used to determine whether the data structure was appropriate for factor analysis in terms of the sample size of the SNAS adult application. As a result of the analysis, KMO value was determined as 0.84. Besides, the Anti-Image Correlation Matrix intersection values were also analyzed and it was found that these values varied between .78 and .91 . As the values at this intersection point were above 0.5 , it was determined that it was accurate to include all the items in the scale.

In order to determine whether the data showed normal distribution or not, Skewness and kurtosis values were examined. Skewness was found .52and Kurtosis was found -06 . The fact that both values are between the range of $-1,+1$ implies that they show normal distribution. Kolmogorov-Smirnov test results ( $\mathrm{p}>.05$ ) also support normal distribution.

\subsubsection{The Validity of SNAS Adult Application}

EFA and CFA were performed for the construct validity of the scale. After the first factor analysis with a total of 30 items, the items were collected in 5 sub-dimensions, with eigenvalues greater than 1 . However, the items numbered 1, 3, 4, 7, 8, 10, 11, 12, 13, 14, 15, 18, 19, 20, 21, $22,24,25,26,27$ with factor loadings below 0.30 and that were overlapping were gradually removed from the scale. Factor analysis was made again by removing one item at each step. As a result, 20 items were removed from the scale and the remaining 10 items were collected in 3 sub-dimensions. The items of each sub-dimension were examined and it was found that they were grouped under the factor to which they were related. To clarify the relationship among factors, direct oblimin rotation (the oblique rotation technique of Principal Component Analysis) was used. Within this context, it was determined that the first factor explained $26.2 \%$, the second factor explained $25.26 \%$ and the third factor explained $19.5 \%$ of the total variance. The total variance explained by the scale was found $70.96 \%$. The findings obtained as a result of the factor analysis performed for SNAS Adult Application reveal that the validity of the scale was sufficient. In addition, it was determined that it had the same factor structure with the adolescent application. The factors formed after EFA for SNAS Adult Application and the factor loadings are given in Table 5.

As can be seen in Table 5, the first factor is composed of three items $(28,29,30)$ and the factor loadings vary between .88 and .90 . The second factor is composed of four items $(2,5,6,9)$ and the factor loading values vary between .71 and .81 . The third factor is composed of three items $(16,17,23)$ and the factor loadings vary between .76 and .80 . 
Table 5. Factor Loadings of SNAS Adult Application

\begin{tabular}{|c|c|c|c|c|c|}
\hline \multirow{2}{*}{ Factors } & & \multirow{2}{*}{ Items } & \multicolumn{3}{|c|}{ Factor Loadings } \\
\hline & & & 1 & 2 & 3 \\
\hline \multirow{4}{*}{$\begin{array}{l}\text { Control } \\
\text { Difficulty }\end{array}$} & Q5 & I make an effort to use social networks every day.(2) & .842 & .023 & -.167 \\
\hline & Q4 & $\begin{array}{l}\text { I find myself surfing the social networks in most of my } \\
\text { daily life.(5) }\end{array}$ & .817 & .057 & .050 \\
\hline & Q6 & I spend most of my time in social networks. (9) & .737 & .022 & .150 \\
\hline & Q7 & $\begin{array}{l}\text { I do not give up using social networks even if they } \\
\text { affect my daily life. (6) }\end{array}$ & .692 & .020 & .186 \\
\hline \multirow{3}{*}{$\begin{array}{c}\text { Negativenes } \\
\mathrm{s} \text { in Social } \\
\text { Relations }\end{array}$} & Q8 & I feel happy to share my ideas on social networks.(23) & .075 & .826 & .008 \\
\hline & Q9 & I express myself better on social networks.(17) & .001 & .792 & .080 \\
\hline & Q10 & $\begin{array}{l}\text { I prefer to share my daily activities on social } \\
\text { networks.(16) }\end{array}$ & .107 & .766 & .095 \\
\hline \multirow{3}{*}{$\begin{array}{l}\text { Decrease in } \\
\text { Functions }\end{array}$} & Q1 & $\begin{array}{l}\text { My performance at work/school have decreased since I } \\
\text { began to use social networks. (28) }\end{array}$ & .049 & .011 & .925 \\
\hline & Q2 & $\begin{array}{l}\text { I have begun to have problems focusing on my } \\
\text { work/school since I began to use social networks.(30) }\end{array}$ & .038 & .043 & .898 \\
\hline & Q3 & $\begin{array}{l}\text { The time I allocate for my work/lessons have decreased } \\
\text { since I began to use social networks.(29) }\end{array}$ & .097 & .012 & .878 \\
\hline
\end{tabular}

Notes: $\mathrm{N}=310 * \mathrm{p}<.05 * * \mathrm{p}<.01$

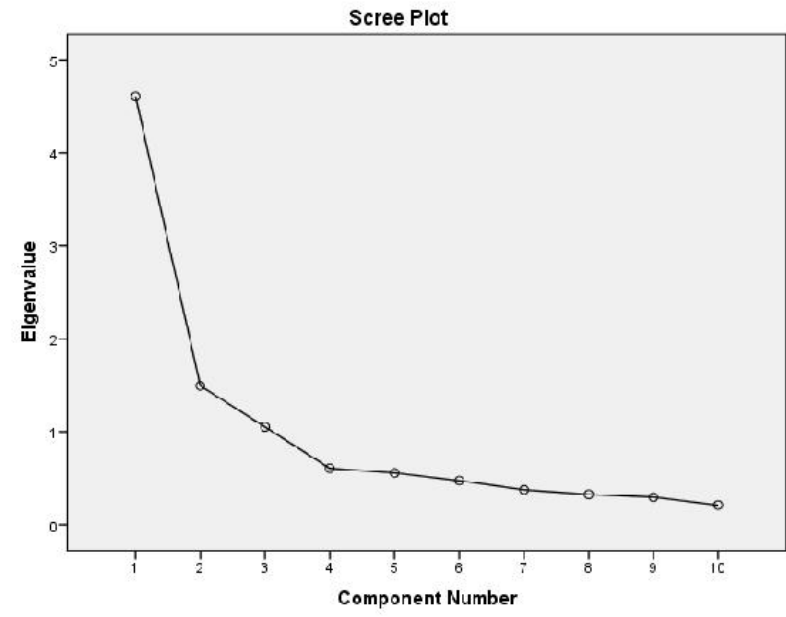

Figure 4. SNAS Adult Application Scree Plot Graph

When the "Scree Plot" graph is examined, it can be seen that the curve shows a sharp decrease till the third factor and that the curve proceeds horizontally after the third factor (Figure 4). The results are consistent with the previous results showing that the scale has a three-factor structure. After this process, it was analyzed whether there were any significant relationships between the factors forming the scale. As a result of Pearson Product-Moment Correlation Analysis conducted to test whether there was a significant relationship among the subdimensions of the scale, consistent with the literature (Andreassen, 2012; Esgi, 2017; Şahin, 2018; Şahin \& Yağc1, 2017; Ülke et al., 2017), it was found that there were positive significant relationships among all the factors of the scale $(\mathrm{p}<.001)$. It was determined that the relationship of "Control Difficulty" factor with "Decrease in Functions" and "Negativeness in Social Relations" factors we as .40 and .47 , respectively, and the relationship between "Decrease in Functions" and "Negativeness in Social Relations" was .23.

First level CFA was performed to determine whether the 10-item, 3-factor structure of the scale achieved after EFA performed for SNAS Adult Application would be verified. 


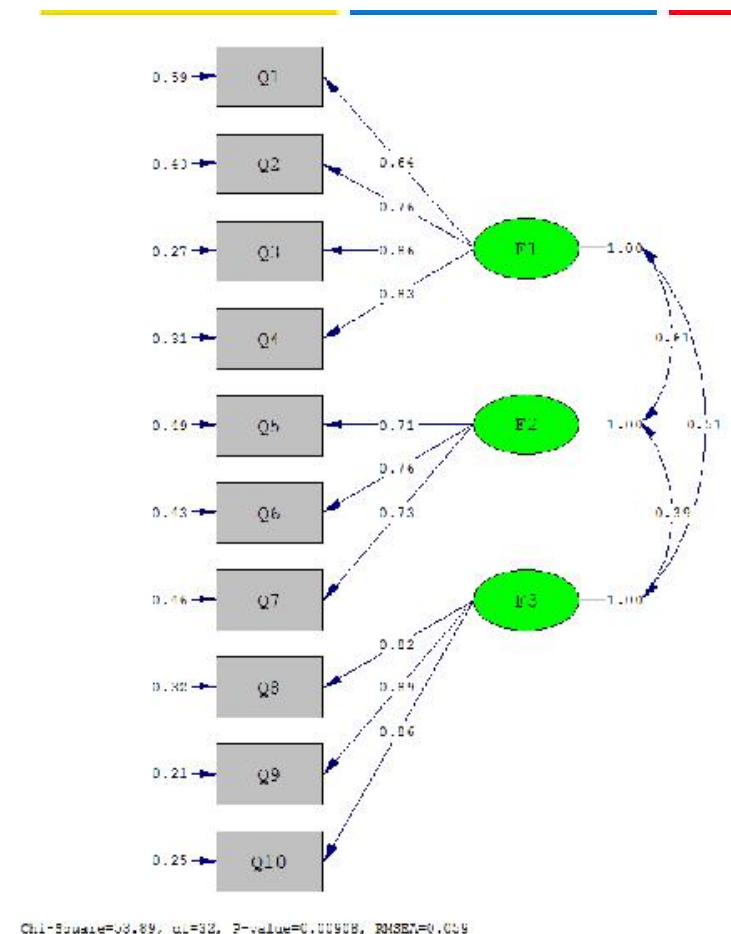

Figure 5. SNAS Adult $1^{\text {st }}$ Level CFA

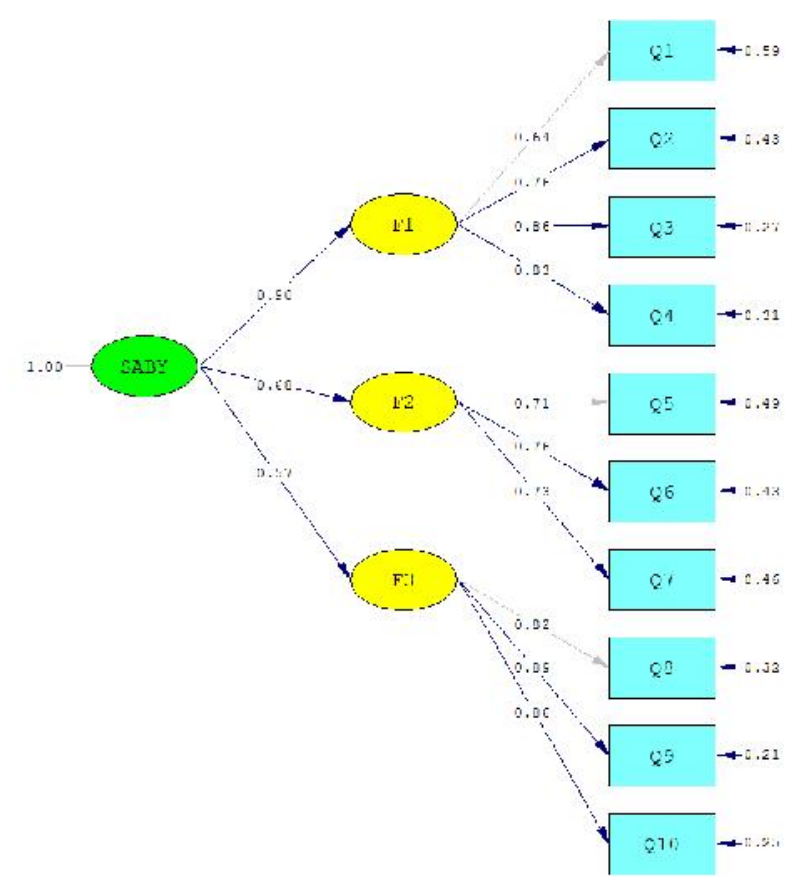

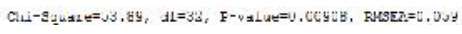

Figure 6. SNAS Adult $2^{\text {nd }}$ Level CFA

As a result of the first level (Figure 5) and second level (Figure 6) CFA performed for SNAS Adult Application, $\chi 2 / s d$ ratio was calculated as $1.68(\chi 2 / s d=53.89 / 32)$ and these values correspond to good fit. It was determined that, of the fit indexes, AGFI was .91, GFI was .95, standardized RMR fit index value was .056, NFI fit index value was .97, and CFI fit index value was .99. RMSEA fit index value for both levels was found as .059. When all the values related to data fit of the model are considered, it can be seen that the model formed shows adequate level of fit with the data.

To compare 1-factor and multifactorial structure, an additional CFA was performed Scale was assumed one dimensional and the obtained fit values $((\chi 2 / \mathrm{sd}=440.25 / 35=12.5, \mathrm{NFI}=0.76$, $\mathrm{GFI}=0.69, \mathrm{CFI}=0.78, \mathrm{RMSEA}=0.24)$ indicated that the 1 -factor structure had poorer fit values than the 3-factor structure. This result supports to the multifactorial structure of SNAS Adult Application.

In order to determine whether the properties of the scale are invariant in different groups, measurement invariance was examined. While the measurement invariance of the factor structure of the scale was being measured for the adolescent and adult sample, multiple-group confirmatory factor analysis was used. For this purpose, 4 hierarchical models; structural invariance, metric invariance, strong invariance and strict invariance, which are commonly used in the literature were tested. In this study, it was examined whether the invariance conditions of CFI $\leq-0.01$ for multiple group confirmatory factor analysis study files which are compatible with the data of were obtained. The fact that CFI value obtained as a result of the comparison of the two models is equal to -.01 or below can be used as the evidence that the measurement equivalence is achieved (Wu et al., 2007).

The findings regarding the invariance steps tested are present in Table 6. "The Structural Invariance Model" in the table represents the factor loads, regression constant and the error variances free model; "The Weak Invariance Model" in the table represents the factor loads constant, regression constants and error variances free model; "The Strong Invariance Model" in the table represents the factor loads, regression constants and error variance free model; and 
"The Strict Invariance Model" in the table represents the factor loads, regression constants and error variances constant model.

Table 6. Fit statistics regarding measurement invariance

\begin{tabular}{lcccccc}
\hline Steps & $\chi 2$ & $\mathrm{~d}$ & $\mathrm{CFI}$ & GFI & RMSEA & CFI \\
\hline Structural Invariance & 87.84 & 67 & .99 & .97 & .031 & - \\
Weak (Metric) Invariance & 44.76 & 32 & 1.00 & 1.00 & .036 & 0.01 \\
Strong (Scalar) Invariance & 44.76 & 32 & 1.00 & 1.00 & .036 & 0.01 \\
Strict Invariance & 87.84 & 87 & 1.00 & .97 & .006 & 0.01 \\
\hline
\end{tabular}

As can be seen in Table 6, the fit indexes obtained as a result of multi-group CFI and CFI values obtained as a result of CFI difference test can be interpreted for each step as follows. According to the results, it is seen that the structural invariance is provided and this finding shows that the measured structures use the same conceptual perspectives in responding to the scale items of the adolescents and adults. The finding regarding the metric invariance indicates that the factor structures of the variables taken in the model are the same in the adolescent and adult groups. It is confirmed that the strong invariance is provided and the constant number in the regression equations formed for the items is invariant between the groups. In the last stage, considering the CFI value calculated with the fit indexes, it is accepted that the error terms regarding the items forming the measurement tool are invariant between the comparison groups. Hierarchical analysis results, factor structure and pattern of the scale, factor loads, regression constants, and error variances are seen to be invariant for the adolescent and adult groups.

For the criterion validity of SNAS Adult Application, the relationship with Internet Addiction Scale was examined. As a result of Pearson Product-Moment Correlation Analysis performed for the criterion validity, it was determined that there was a positive ( $\mathrm{r}=.65)$ and statistically significant relationship ( $\mathrm{p} \leq 001)$ between the scales.

\subsubsection{Reliability Studies}

Reliability analyses were performed both for the overall and for the factors of SNAS Adult Application. On the condition that the items are congeneric measurements, McDonald Omega coefficient is used (McDonald, 1999). McDonald Omega coefficient of the overall scale was calculated as .91. McDonald Omega value for the first factor was .83; item total correlation coefficients varied between .78 and .84. For the second factor, McDonald Omega value was .76; item total correlation coefficients varied between .54 and .73. For the third factor, McDonald Omega value was .91; item total correlation coefficients varied between .52 and .55. As all the values in the reliability analysis both for the overall and for the factors of SNAS Adult Application are above 0.70 , it can be said that the reliability of the scale is high. In the reliability analysis for the 10 items included in the scale, the item total correlation coefficients of the items varied between .37 and .66 .

Item analysis was performed to determine whether there was a difference between the responses of the individuals with low scores (the lower 27\% group) and high scores (the upper $27 \%$ group). As a result of the $t$ test performed for this purpose, it was observed that $t$ values of the items varied between $6.09(\mathrm{p}<.001)$ and $21.03(\mathrm{p}<.001)$ and there was a significant difference.

Within the framework of Item Response Theory, item difficulty (a), item discrimination power (b) and item-model fit $\left(X^{2}\right)$ was examined and the results are given in Table 7.

When Table 7 is analyzed, the fact that all the values are above 1 reveals that the items have good level of discrimination. High level of " $b$ " value exhibits that the item is functional or it measures among the individuals with high addiction levels, whereas low level of " $b$ " value indicates that the item is functional or it measures among the individuals with low addiction 
levels. Item difficulty value varies between -2.32 and 3.26. It was noted that while the first threshold value of the scale (Likert 1 and 2 interval) was between 0 and 1, the second threshold value varied between 0 and 1, the third threshold value varied between 1 and 2, and the fourth threshold value varied between 2 and 3. This suggests that the scale is better discriminated in the individuals with high social network addiction. The fact that all the $X^{2}$ values indicating item model fit are insignificant shows that all the items meet the model fit.

Table 7. Parameter values in terms of SNAS Adult Application according to IRT

\begin{tabular}{cccccccccccccc}
\hline Item & $a$ & s.e. & $b_{1}$ & s.e. & $b_{2}$ & s.e. & $b_{3}$ & s.e. & $b_{4}$ & s.e. & $X^{2}$ & $d f$ & $p$ \\
\hline 1 & 1.53 & 0.22 & -2.32 & 0.33 & -1.35 & 0.22 & -0.15 & 0.14 & 0.59 & 0.15 & 54.65 & 45 & 0.153 \\
2 & 2.08 & 0.28 & -0.77 & 0.16 & 0.09 & 0.12 & 1.11 & 0.14 & 1.72 & 0.19 & 53.93 & 44 & 0.144 \\
3 & 2.43 & 0.34 & -1.14 & 0.16 & -0.38 & 0.12 & 0.40 & 0.11 & 1.45 & 0.16 & 60.30 & 44 & 0.051 \\
4 & 3.00 & 0.43 & -0.61 & 0.13 & 0.29 & 0.11 & 0.97 & 0.12 & 1.71 & 0.17 & 48.88 & 38 & 0.110 \\
5 & 1.27 & 0.20 & -1.01 & 0.22 & 0.78 & 0.16 & 1.96 & 0.28 & 3.26 & 0.51 & 49.03 & 45 & 0.314 \\
6 & 1.35 & 0.22 & -0.21 & 0.16 & 0.83 & 0.16 & 1.92 & 0.27 & 3.10 & 0.47 & 51.97 & 46 & 0.252 \\
7 & 1.01 & 0.18 & -0.82 & 0.23 & 0.65 & 0.19 & 1.91 & 0.33 & 3.20 & 0.56 & 70.70 & 52 & 0.053 \\
8 & 1.73 & 0.35 & 0.66 & 0.13 & 1.76 & 0.23 & 2.38 & 0.34 & 3.16 & 0.54 & 33.63 & 30 & 0.295 \\
9 & 1.63 & 0.31 & 0.21 & 0.13 & 1.34 & 0.18 & 2.35 & 0.33 & 2.91 & 0.45 & 52.26 & 37 & 0.049 \\
10 & 1.70 & 0.33 & 0.47 & 0.12 & 1.35 & 0.18 & 2.07 & 0.28 & 2.83 & 0.43 & 44.54 & 39 & 0.249 \\
\hline
\end{tabular}

\section{DISCUSSION and CONCLUSION}

The presence of social network addiction can be discussed depending on the definition of addiction used. However, there are evidences that some social network users are experiencing addiction-like symptoms due to excessive use. Besides, many studies have revealed that social networks are addictive (eg. Echeburúa \& de Corral, 2010; Grffiths, Kuss, \& Demetrovics, 2014; Pantic, 2014; Ryan et al., 2014). It can be seen in the literature that the researchers investigating social network addiction focus primarily on Facebook addiction (Andreassen, 2015). However, it has been discussed that Facebook is just a social network and therefore, there is a need for valid scales involving other social network sand measuring social network addiction (Griffiths et al., 2014). Although social networks, which can be considered as the sub-dimension of the internet, have some similar characteristics in terms of their intended use, they differ in the uses specific to individual and purpose (Kuşay, 2013; Van den Eijnden et al., 2016).

When the literature was examined, it could be seen that the scales developed differed in terms of factor structures and target groups and the total variance range explained varied between 35\% and 59\% (Esgi, 2016; Firat, \& Barut, 2018; Şahin, 2018; Şahin, \& Yağc1, 2017; Taş, 2017; Tutgun-Ünal, 2015; Tutgun-Ünal, \& Deniz, 2015; Ülke, Noyan, \& Dilbaz, 2017; Van den Eijnden et al., 2016). The factor structures of these scales, which were developed for different age groups differed from each other. On the other hand, the factor structure of the social media addiction scale, which was developed by Bakır Ayğar \& Uzun (2018) and whose target group was university students, was similar to the factor structure of SNAS. As could be seen, each scale was structured according to different age groups and their factor structures differed from each other. Besides, for the criterion validity in the measurement tools developed to measure social network addiction, Bakır Ayğar \& Uzun (2018) used the problematic internet use scale; and Van den Eijnden et al. (2016) used compulsive internet use scale. In both studies, it was determined that the correlation with the scale used for the criterion validity was high. The criterion validity was not examined in the other scales developed for social network addiction (Eşgi, 2017; Şahin, 2017; Şahin \& Yağc1, 2016). 
The scales in the literature are generally dispersed in terms of target groups and factor structures. This situation is thought to have a negative effect on the comprehensive comparability between the developmental periods regarding social network addiction. SNAS developed in this study is significant in terms of sorting out this problem.

The factor structures of SNAS, which was composed of a total of 10 items, were named as "Control Difficulty", "Decrease in Functions" and "Negativeness in Social Relations".

As a result of the factor analysis performed, the total variance explained and factor load values were high in adolescent and adult form. The first level CFA and second level CFA results of the scale revealed that the model showed adequate fit with the data. McDodalds Omega reliability coefficient values for each sub-dimension, which was conducted to determine the reliability of the scale, also showed that the scale was reliable. Furthermore, IRT was used to confirm the reliability results obtained. As a result of this analysis, it was found that only the item number 9 in the adolescent form was weak in terms of discrimination. However, due to the fact that it was too close to the acceptable value and that both the factor load value and the total correlation coefficient were high, the item was not excluded from the scale. As a result of Pearson Product Moment Correlation Analysis performed for the criterion validity of adolescent and adult forms, a positive and statistically significant relationship was found between the scales. The highest score that can be obtained from the scale is 50 and the lowest score is 10 . As the score obtained from the scale goes up to 50, addiction level increases, too. The scale developed involves adolescents, young adults and adults between 14-45 years of age.

The scale has great power of explaining the variable it intends to measure with a small number of well-working items. With this feature, the scale will provide researchers convenience and flexibility with the researches targeting different age groups and for possible comparisons.

Orcid

brahim GÖKDAŞ (iD https://orcid.org/0000-0001-7019-8735

Yaşar KUZUCU (DD https://orcid.org/0000-0002-8487-9993

\section{REFERENCES}

Aksu, G., Eser, M. T., \& Güzeller, C. O. (2017). Açımlayıcı ve Doğrulayıcı Faktör Analizi ile Yapısal Eşitlik Modeli Uygulamaları. Ankara: Detay yayıncılık.

Allen, K. A., Ryan, T., Gray, D. L., Mclnerney, D. M., \& Waters, L. (2014). Social media use and social connectedness in adolescents: The positives and the potential pitfalls. The Australian Educational and Developmental Psychologist, 31, 18 - 31. https://doi.org/10. 1017/edp.2014.2

Andreassen, C. S. (2015). Online social network site addiction: A comprehensive review. Technology and Addiction (M Griffiths, Section Editor). Current Addiction Reports. 2, 175-184. DOI 10.1007/s40429-015-0056-9

Augner, C., \& Hacker, G.W. (2012). Associations between problematic mobile phone use and psychological parameters in young adults. International Journal of Public Health. 57(2), 437-41. DOI: 10.1007/s00038-011-0234-z

APA (American Psychiatric Association). (2013). Diagnostic and Statistical Manual of Mental Disorders (DSM-5). American Psychiatric Association Publishing.

Ayğar Bakır, B. \& Uzun, B. (2018). Sosyal Medya Bağımlılı̆̆ı Ölçeği’nin geliştirilmesi: Geçerlik ve güvenirlik çalışmaları. [Developing the Social Media Addiction Scale: Validity and Reliability Studies] Addicta: The Turkish Journal on Addictions, 5, 507 525. http://dx.doi.org/10.15805/addicta.2018.5.3.0046 
boyd, D. M., \& Ellison, N. B. (2007). Social network sites: Definition, history, and scholarship. Journal of Computer - Mediated Communication, 13, 2010 - 2030. https://doi.org/10.11 11/j.1083-6101.2007.00393.x

Brunborg, G. S., Mentzoni, R. A., Molde, H., Myrseth, H., Skouverøe, K. J. M., Bjorvatn, B., \& Pallesen, S. (2011). The relationship between media use in the bedroom, sleep habits, and symptoms of insomnia. Journal of Sleep Research, 20, 569-575. https://doi.org/10.1111/j.1365-2869.2011.00913.x

Cakir Balta, O. \& Horzum M. B. (2008). nternet bağımlılı̆̆ı testi. [Internet addiction test]. Eğitim Bilimleri ve Uygulama, 7(13), 87-102

Can, L., \& Kaya, N. (2016). Social networking sites addiction and the effect of attitude towards social network advertising. Procedia-Social and Behavioral Sciences, 235, 484-492. https://doi.org/10.1016/j.sbspro.2016.11.059

Cao, F., \& Su, L., (2006). Internet addiction among Chinese adolescents: prevalence and psychological features. Child Care Health and Development. 33(3), 275-281. https://doi.org/10.1111/j.1365-2214.2006.00715.x

Cecilia, C., \& Yee-lam L. A., (2014). Internet addiction prevalence and quality of (real) life: a meta-analysis of 31 nations across seven world regions, Cyberpsychology, Behavior, and Social Networking. 17(12), 755-760.

Cheung, L. M., \& Wong, W. S. (2011). The effects of insomnia and internet addiction on depression in Hong Kong Chinese adolescents: An exploratory cross-sectional analysis. Journal of Sleep Research, 20, 311-317. http://dx.doi.org/10.1111/j.13652869.2010.00883.x

Choi, S. B., \& Lim, M. S. (2016). Effects of social and technology overload on psychological well-being in young South Korean adults: The mediatory role ofsocial network service addiction. Computers in Human Behavior, 61, 245-254.

Çokluk, Ö., Şekercioğlu, G., \& Büyüköztürk, Ş. (2012). Sosyal Bilimler için Çok Değişkenli İstatistik SPSS ve LISREL Uygulamaları. Ankara: Pegem Akademi.

De Beer, M. (2004). Use of differential item functioning (DIF) analysis for bias analysis intest construction. South African Journal of Industrial Psychology, 30(4), 52-58.

Dewald, J. F., Meijer, A. M., Oort, F. J., Kerkhof, G. A., \& Bögels, S. M. (2010) The influence of sleep quality, sleep duration and sleepiness on school performance in children and adolescents: a meta-analytic review. Sleep Medicine Reviews, 14, 179-189.

Echeburúa, E., \& De, Corral. P. (2010). Addiction to new technologies and to online socialnetworking in young people: A new challenge. Adicciones, 22(2), 91-95.

Erkuş, A. (2012). Psikolojide Ölçme ve Ölçek Geliştirme-1 temel kavramlar ve işlemler. Ankara: Pegem Akademi.

Esgi, N. (2016). Development of social media addiction test (SMART17). Journal of education and training studies. 4(10), 174-181

Gao, W., Liu, Z., \& Li, J. (2017). How does social presence influence SNS addiction? A belongingness theory perspective. Computers in Human Behavior 77 (2017) 347-355. http://dx.doi.org/10.1016/j.chb.2017.09.002

Griffiths, M. D. (2013). Social networking addiction: emerging themes and issues. Journal of Addiction Research \& Therapy, 4(5). http://dx.doi.org/10.4172/2155-6105.1000e118

Griffiths, M. D., Kuss, D. J., \& Demetrovics, Z. (2014). Social networking addiction: anoverview of preliminary findings. In Behavioral addictions. Criteria, evidence, and treatment (pp. 119-141). New York: Elsevier. 
Gültaş, M. (2014). Work Discipline Compound Personality Scale Development with Item Response Theory. Unpublished dissertation thesis. Middle East Technical University, Graduate School of Social Sciences, Ankara.

Huang, H., \& Leung, L. (2009). Instant messaging addiction among teenagers in China: Shyness, alienation, and academic performance decrement. Cyberpsychology and Behavior, 12(6), 675-679. http://dx.doi.org/10.1089/cpb.2009.0060

Huang, X., Zhang, H., Li, M., Wang, J., Zhang, Y., \& Tao, R., (2010). Mental health, personality, and parental rearing styles of adolescents with internet addiction disorder. Cyberpsychology, Behavior, and Social Networking. 13(4), 401-406. DOI: 10.1089=cyber. 2009.0222

Kang, I., Shin, M. M., \& Park, C. (2013). Internet addiction as a manageable resource:A focus on social network services. Online Information Review, 37(1), 28-41.

Kim, E. J., Namkoong, K., Ku, T., \& Kim, S.J., (2008). The relationship between online game addiction and aggression, self-control and narcissistic personalitytraits. European Pschiatry, 23, 212-218.

Kim, K., Ryu, E., Chon, M. Y., Yeun, E. J., Choi, S. Y., Seo, J. S., \&Nam, B.W., (2006). Internet addiction in Korean adolescents and its relation to depression andsuicidal ideation: a questionnaire survey. Intertional Journal of Nursing Studies, 43, 185-192.

Kuss, D. J., \& Griffiths, M. D. (2011). Online social networking and addiction-A review of the psychological literature. International Journal of Environmental Research and Public Health, 8, 3528-3552. DOI:10.3390/ijerph8093528

Kuss, D. J., \& Griffiths, M. D. (2012). Internet gaming addiction: A systematic reviewof empirical research. International Journal of Mental Health and Addiction, 10(2), 278296.

Kuşay, Y. (2013). Sosyal Medya Ortamında Çekicilik ve Bağımlılık-Facebook Üzerine Bir Araştırma. stanbul: Beta Yayıncılık.

LaRose, R., Connolly, R., Lee, H., Li, K., \& Hales, K. D. (2014). Connection overload? Across cultural study of the consequences of social media connection. Information Systems Management, 31(1), 59-73. https://doi.org/10.1080/10580530.2014.854097

Lavin, M. J., Yuen, C.N., Weinman, M., \& Kozak, K., (2004). Internet dependence in the collegiate population: The role of shyness. CyberPsychology \& Behavior. 7, 379-383.

Pantic, I. (2014). Online social networking and mental health. Cyberpsychology, Behavior, and Social Networking, 17(10), 652-657. DOI: 10.1089/cyber.2014.0070

Park, S. K., Kim, J. Y., \& Cho, C. B. (2008). Prevalence of Internet addiction and correlations with family factors among South Korean adolescents. Adolescence,43(172), 895-909.

Ryan, T., Chester, A., Reece, J., \& Xenos, S. (2014). The uses and abuses of Facebook: A review of Facebook addiction. Journal of Behavioral Addictions 3(3), 133-148. DOI: 10.1556/JBA.3.2014.016

Salehan, M., \& Negahban, A. (2013). Social networking on smartphones: Whenmobile phones become addictive. Computers in Human Behavior, 29(6), 2632-2639.

Satici, S. A., \& Uysal, R. (2015). Well-being and problematic Facebook use. Computers in Human Behavior, 49, 185-190. DOI:10.1016/j.chb.2015.03.005

Suganuma, N., Kikuchi, T., Yanagi, K., Yamamura, S., Morishima, H., Adachi, H., Kumanogo, T., Mikami, A., Sugita, Y., \& Takeda, M. (2007). Using electronic media before sleep can curtail sleep time and result in self-perceived insufficient sleep. Sleep and Biological Rhythms, 5, 204-214. 
Şahin, C. (2018). Social media addiction scale - Student form: The reliability and validity study, TOJET: The Turkish Online Journal of Educational Technology,17(1), 169-182. ERIC Number: EJ1165731

Şahin, C., \& Yağcı, M. (2017). Sosyal medya bağımlılı̆̆ı ölçeği- Yetişkin formu: Geçerlilik ve güvenirlik çalışması [Social Media Addiction Scale - Adult Form: The Reliability and Validity Study Social Media Addiction Scale - Adult Form: The Reliability and Validity Study], Ahi Evran Üniversitesi Kırşehir Eğitim Fakültesi Dergisi (KEFAD), 18(1), 523538.

Taş, . (2017). Ergenler için sosyal medya bağımlılığı ölçeği kısa formunun (SMBÖ-KF) geçerlik ve güvenirlik çalışması, [The Study of Validity And Reliability of The Social Media Addiction Scale Short Form For Adolescents], Online Journal of Technology Addiction \& Cyberbullying, 4(1), 27-40.

Tekin, C., Gunes, G., \& Colak, C. (2014). Adaptation of problematic mobile phone use scale to Turkish: a validity and reliability study. Medicine Science, 3(3), 1361-81. DOI: 10.5455/medscience.2014.03.8138

Turel, O., \& Serenko, A. (2012). The benefits and dangers of enjoyment with socialnetworking websites. European Journal of Information Systems, 21(5), 512-528.

Tutgun-Ünal, A. (2015). Sosyal medya bağımlılığı: üniversite öğrencileri üzerine bir araştırma. [Social media addiction: a research on university Students], (Yayınlanmamış Doktora Tezi) Marmara Üniversitesi Sosyal Bilimler Enstitüsü, Gazetecilik Ana Bilim Dalı, Bilişim Bilim Dalı. stanbul.

Van den Eijnden, R. J. J. M., Lemmens, J. S., \& Valkenburg, P. M. (2016). The social media disorder scale. Computers in Human Behavior, 61, 478-487.

Vilca, L. W., \& Vallejos, M. (2015). Construction of the risk of addiction to socialnetworks scale (Cr. ARS). Computers in Human Behavior, 48, 190-198.

We are Social (2017). Digital in 2017 Global Overview Report. https://wearesocial.com/uk/special-reports/digital-in-2017-global-overview

Wu, A. D., Li, Z. ve Zumbo, B. D. (2007). Decoding the meaning of factorial invariance and updating the practice of multi-group confirmatory factor analysis: A demonstration with TIMSS data. Practical Assessment, Research \& Evaluation, 12, 1-26.

Yang, S., Liu, Y., \& Wei, J. (2016). Social capital on mobile SNS addiction: A perspective from online and offline channel integrations. Internet Research, 26(4), 982-1000.

Young, K. S. (1998). Internet addiction: The emergence of a new clinical disorder. Cyberpsychology and Behavior, 1(3), 237-244. https://doi.org/10.1089/cpb.1998.1.237 